\title{
THE ROLE OF ENVIRONMENT REGULATION ON FIRMS' PRIVATE ACTION ON ENVIRONMENTAL QUALITY: CASE OF NON-ADOPTION OF SOLID WASTE MANAGEMENT PRACTICES BY FOOD PROCESSING SECTOR IN SRI LANKA
}

\author{
J. M. M. Udugama and U. K. Jayasinghe-Mudalige* \\ Department of Agribusiness Management, Wayamba University of Sri Lanka \\ udith@ hotmail.com*
}

\begin{abstract}
The purpose of this study was to examine empirically extent to which the regulatory framework and the legal system on environment have an impact on firms' private action on environment quality using the case of Sri Lankan food processing firms' non-compliance to the 9 different solid waste management practices (SWMPs) recommended by the Ministry of Environment for a firm to adopt based on the production and processing activities it undertakes. The perceptions of managers of 160 firms that did not adopt a single SWMP were assessed by means of an index - "Environment Regulation Responsiveness Index" (ERRI) of which the values reflects the relative strength of the firm in concern perceived on the environmental regulation (i.e. -1.0 the least to 1.0 the most responsive). The outcome of analysis highlights that the magnitude of ERRI of the majority of firms was relatively low (i.e. in between -0.5 to 0.5 ), especially for the small scale firms, suggesting that firms did not consider the government regulation as a promising factor to act on the environment. This calls for a critical revision and adjustments to the policy on environmental quality management both at the national and provincial level in order to promote voluntary action by firms.
\end{abstract}

Keywords: Compliance, Environmental quality, Food processing sector, Regulation, Solid waste management

\section{INTRODUCTION}

The economic problem of whether a firm can be considered as a "black box" that translates regulatory inputs into compliance outputs in a straightforward manner was in the minds of the economists for a longer time (Henson and Heasman, 1998) as many implicitly assumed that the internal systems within the firms can easily generate the desired changes to achieve compliance and that non-compliance is a "rogue" outcome. When faced with a new regulation, according to Henson and Heasman (1998), firm's compliance decision does not involve a simple question as to whether comply or not, because it is closely related to decisions regarding 'how to comply' since a continuum of responses is available with it, ranging from 'full compliance' to 'non-compliance'.

Regulation has, thus, become a major element of the environment in which firms operate that can constraint the strategic behavior of firms (Porter and van Linde, 1995) and the food industry is one example of this. In regulating businesses by way of public legislation, according to Stigler (1971), governments force them to operate within certain constraints when the social costs of private market activity are considered great and government action is needed to mitigate a market defect. Capture theory suggests that firms may attempt to co-options the regulatory process in an attempt to gain strategic advantage and this can occur at the level of the individual firm or the industry through, for example, interest groups (Peltzman, 1976).

The interrelationship between the regulatory activities of government and the strategic behavior of firms is well recognized in the environmental and food economics literature though the vast majority of previous analyses on which were focused on the workings of food markets in the developed countries (Marcus, 1984), for example, reports three main strategic choices faced by a firm in its response to environmental regulation, including: (a) stonewalling - where the firm attempts to ignore or ride out the problems created by the regulation; (b) opportunity seeking - where the firm sees the 
regulation as an opportunity to gain competitive or other advantages, and (c) a mixed strategy - where new product development and heavy marketing might characterize firm's response to regulation. Porter and van Linde (1995) argue that firms who adapt quickly to new, more stringent regulations gain a type of 'first mover' advantage in the market place, which leaves them better able to compete, particularly when these regulations become more widely adopted.

However, cooperate response of firms with regard to compliance to regulation may depend on the expected economic benefits in terms of improvements in industrial performance (i.e. market share and profitability) or by sanctions associated with non-compliance (Rugman and Verbeke, 1998). In the case of former, firms may choose to comply voluntarily, whilst in the latter case compliance depends on the strength of enforcement authorities. Nehrt (1998) emphasizes that firms could benefit strategically from regulation in view of the fact that costs of compliance differ according to efficiency in compliance, which, in turn related to factors such as type and size of the firm as it creates opportunities for large firms, in general, to obtain first-mover advantage, to enhance competitiveness relative to other firms in the market, and to erect barriers to entry or mobility.

Whether a firm takes private actions to augment environment quality, which is more often than not showing characteristics of a public good, in a situation where it can compensate the less significant losses in the market with relatively higher gains obtained through failures in government policy is examined in this study using an empirical approach. We use the special case of Sri Lankan food processing firms' non-compliance to the recently introduced National Strategy for Solid Waste Management of the Ministry of Environment for this analysis, where the Ministry recommends 9 different solid waste management practices (SWMPs) for a food firm to adopt by taking into account of various production and processing activities it undertakes.

\section{METHODOLOGY}

\subsection{DEVELOPMENT OF AN INDEX TO REFLECT FIRM'S PERCEPTION ON REGULATION}

The idea was to develop an index - herein referred to as "Environment Regulation Responsiveness Index" (ERRI) - that has an ability to show extent to which a manager of a firm that did not adopt even a single practice out of 9 recommended is perceived on various aspects pertaining to the firm's response to regulation, i.e. the existing and anticipated regulatory frameworks and the workings of the legal/judiciary system of the country to protect the environment. To facilitate that, we have developed a series of statements $(n=14)$ reflecting different facets of environmental regulation as follows (Table $1)$.

Having formulated the set of statements, we should be clear that all these statements were loaded into a single factor by eliminating the empirical issues associated with quantifying attitudes and perceptions of respondents to derive an index, including the endogeneity, mutual exclusivity, subjectivity and unobservability, or in other words, testing of these statements for their unidimensionality (Hair et al., 2006). The Principle Component Analysis (PCA), which is an interdependence technique stated under the Multivariate Data Analysis techniques that is used commonly to define the underlying structure among a set of variables of an analysis objectively, was employed to test this condition. The PCA techniques helps particularly to find a way to condense the information contained in these 14 statements (i.e. original variables) into a smaller set of new composite dimensions or variates with a minimum loss of information by taking into account of the total variance amongst the original variables (De Vellis, 1991). In principle, the ERRI was specified to meet the characteristics of a Weighted Additive Index (Powers and Xie, 1999) in the form of:

$$
\operatorname{ERRI}_{i}=\sum_{i=1}^{n} W_{s}\left[a\left(R_{s}\right)_{i}\right] /\left[a\left(R_{s}\right)\right]
$$


Table 1: Attitudinal statements reflecting regulation and the outcome of PCA

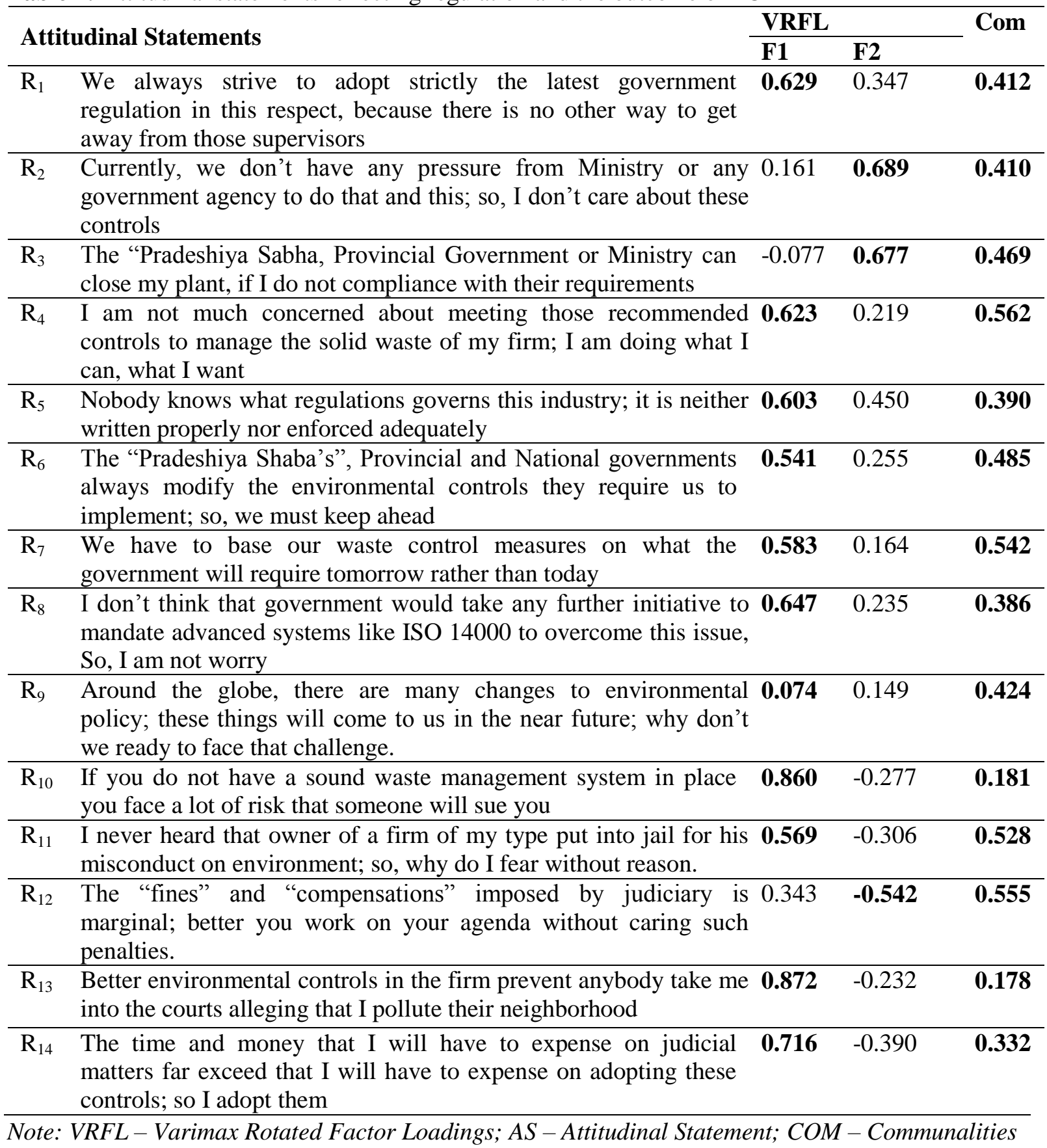

Where, the term a $\left(\mathrm{R}_{s}\right)_{i}$ denotes the score given by a respondent $(i)$ to a statement $\left(\mathrm{R}_{\mathrm{s}}\right)[\mathrm{s}=$ number of statements] on the likert-scale. To derive ERRI for a given firm, the summation of scores of all the statements ( $s=14)$ was divided by the Maximum Potential Score $\left[a\left(R_{s}\right)\right]$ to normalize the value of the index. For this particular analysis, the value of $\left[a\left(R_{s}\right)\right]$ was 70 (i.e. maximum score of +5 on the likert-scale $\mathrm{x} 14$ statements]. With the normalization, the values of ERRI for a given firm, thus, ranges from -1 to 1 , where -1 reflects the "perfect perceptions of the decision maker towards compliance to regulation", and 1 on the other extreme reflects his/her "perfect perceptions towards non-compliance to regulation".

Extent to which the managers' perceived on the effect of each attitudinal statement on their decision to adopt SWMPs in the firm was of an interest in the empirical analysis. Logically, even under the circumstances where the 14 attitudinal statements stated originally were confined to a single variate 
(i.e. unidimensionality), all the respondents in the sample may not value the underlying phenomenon explained in a given statement is as equally important for them to be altruistic towards the environment. If so, it is imperative to incorporate this variation into the analysis. To fulfill this condition, we have weighted the index using appropriate weights (W) taken from the results of the Factor Analysis, i.e. all things equal to ERRI expressed earlier, the term W in above equation represents the weight assigned to each statement to characterize the variation of responses of respondents.

\subsection{STUDY AREA AND THE DATA}

From a database maintained for the research project SANDEE/Jan 08/002 funded by the South Asian Network for Development and Environmental Economics (SANDEE), we have selected 160 agri-food processing firms which did not have even the "most economical" practices out of the 9 SWMPs recommended by the Ministry in place, i.e.: (1) sorting of waste based on 3R system; (2) composting and (3) good manufacturing practices (GMP). The data were collected between May and June 2010 by means of a series of face-to-face interviews with the owner or the top most executive responsible for the firm's decision on environmental aspects. The data collection was supported by a structured questionnaire and carried out in the Central, North-Western, Southern and Western provinces.

The firms included in the sample covered five product categories: (1) coconut products (COP); (2) essential oils (ESO); (3) non-alcoholic beverages (NAB); (4) other processed products (OPP), and (5) processed fruit and vegetables (PFV) and were also categorized as "Large" firms (LRG) and "Small" firms (SML) based on the annual returns. The sample consists of $98(61 \%)$ and $62(39 \%)$ of Small and Large scale firms and 20 (13\%), 44 (28\%), 25 (16\%), 47 (29\%) and 24 (15\%) of COP, ESO, NAB, OPP and PFV firms, respectively.

\section{RESULTS AND DISCUSSION}

\subsection{OUTCOME OF THE CONFIRMATORY FACTOR ANALYSIS}

The Confirmatory Factor Analysis carried out using the scores provided by 160 respondents to 14 statements on the five-point multidirectional likert-scale (i.e. -5 to +5 ) helped to extract two different factors (see, Table 1). This highlights that the scores provided by respondents to these statements were multidimensional.

\subsection{DERIVATION OF ERRI}

Given the multidimensional nature of statements, the scores given to the statements loaded into a given factor (e.g. statements $R_{1}, R_{4}, R_{5}, R_{6}, R_{7}, R_{8}, R_{9}, R_{10}, R_{11}, R_{13}$ and $R_{14}$ for the Factor $1 ; R_{2}, R_{3}$ and $\mathrm{R}_{12}$ for the Factor 2) were taken separately to obtain the relative weight of the respective factor so that the value of ERRI would truly reflect the varying levels of perceptions the respondents in the sample possess for statements written on various issues pertaining to environmental regulation.

Figure 1 shows that Mean value of scores obtained by each statement. The lowest value was given to $\mathrm{R}_{13}$ ("Better environmental controls in the firm prevent anybody take me into the courts alleging that I pollute their neighborhood") implies that the inefficiencies in penalties (i.e. fines and compensations) and lack of community awareness in terms regulations are major determinants affecting non adoption of these controls. The response by firms of different size to certain statements varied significantly, for example, the difference of ERRI between large to small was very high with regard to the statement $\mathrm{R}_{10}$ : "If you do not have a sound waste management system in place you face a lot of risk that someone will sue you" highlighting the impact of liability laws on different firm sizes. 


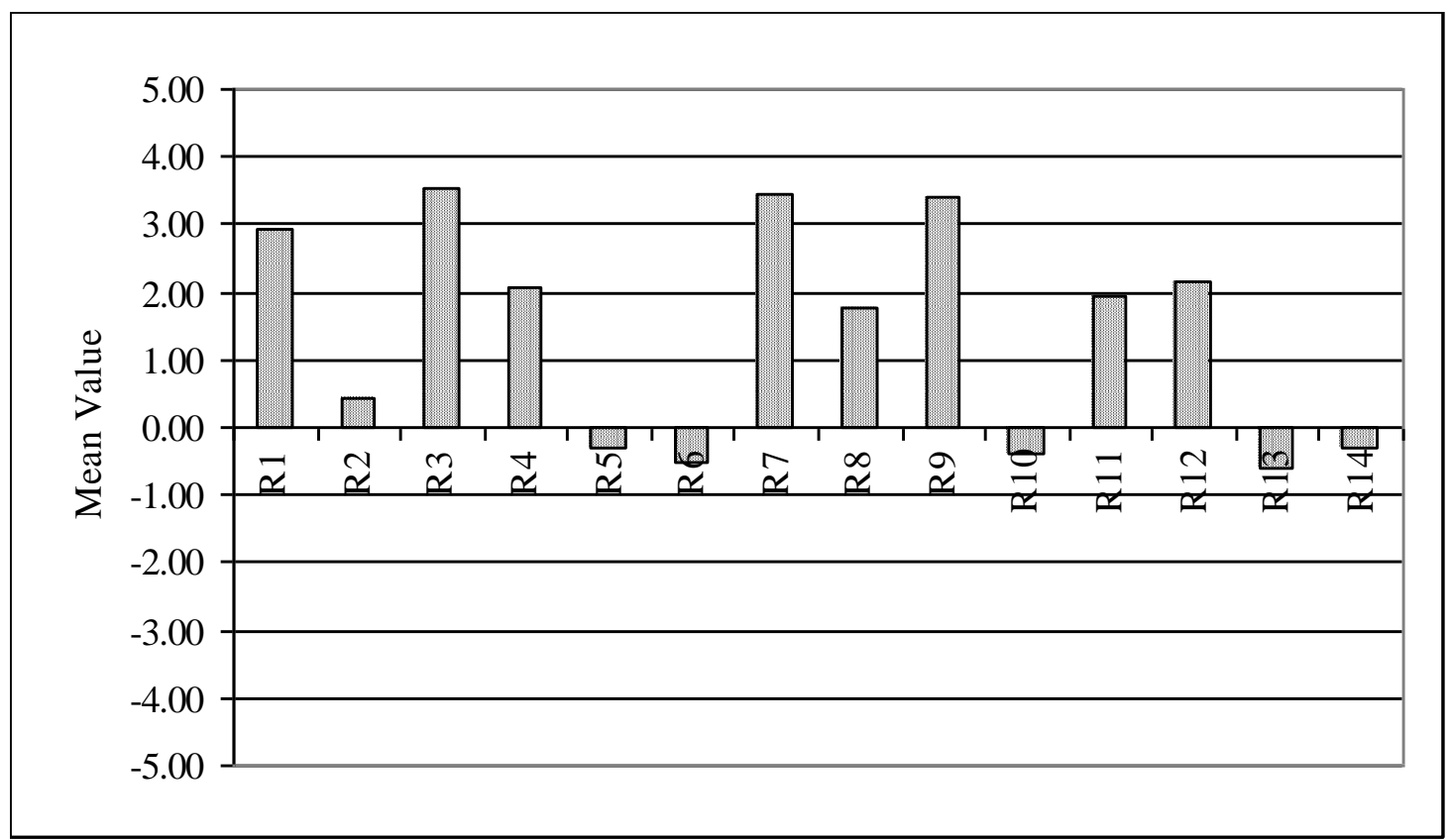

Figure 1: Mean values of the attitudinal statements

The responsiveness to the regulations varied significantly with the firm type within a low range. Among the different types, the Coconut sector had a relatively higher responsiveness while for other types of firms the affinity varied significantly i.e. for the statement $\mathrm{R}_{5}$ : "Nobody knows what regulations governs this industry; it is neither written properly nor enforced adequately" the responses varied drastically implying the lack of awareness and interest on regulation information irrespective of the firm type.

The outcome of analysis shows that the magnitude of ERRI of a majority of the firms was relatively low (i.e. in between 0 to 0.4). This is pretty much clear in the context of firm size, where the value of which of the small scale firms were relatively low indicating that these firms' did not consider the government regulation as a promising factor governing their action on environment (Figure 2).

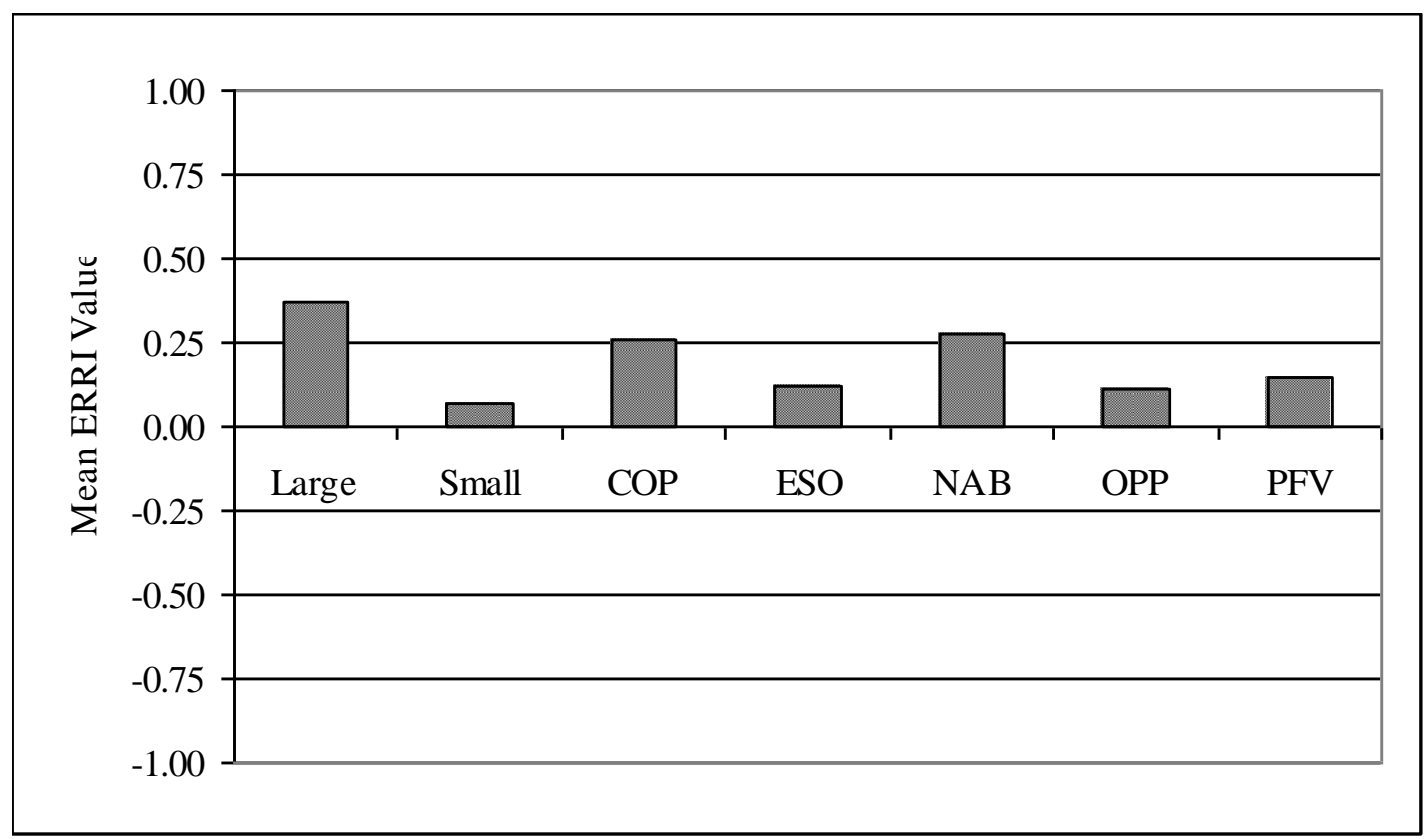

Figure 2: Mean values of ERRI for different sub samples

However, the large firms, though with relatively low values, showed a positive response towards environmental regulations due to many reasons such the likelihood to undertake actions to reduce 
their environmental impacts if made mandatory by the regulatory framework. The majority of the small firms showed relatively low responsiveness towards regulations other than for the statements reflecting existing government regulations. Though not adopted, large firms showed higher positive values for statements reflecting anticipated regulations implying the fact there is potential for the adoption of recommended practices in the future.

\section{CONCLUSIONS AND POLICY IMPLICATIONS}

The outcome of the analysis suggests that firms do not consider the regulatory framework of the government a promising factor governing their action on environment. It also highlights that a vast majority $(>90 \%)$ of firms have "no plans" to adopt any of these practices in the near future citing the financial burden and the lack of information on SWMPs. Further, it could be concluded that the firms in the agri-food processing industry show low levels of responsiveness to regulations irrespective of the firm size/type which may have caused the non-adoption of SWMPs. Further, the firm's decision to "not adopt" these practices even after three years time of introducing the regulation highlights the lack of strength of the regulatory framework in stimulating adoption. From an economic perspective, regulators would aim to maximize welfare when enforcing a regulation. However, many plants avoid complying with environmental regulations because monitoring and enforcement are infrequent. Indeed, the outcome of analysis implies that conventional policy discussion on environmental quality management at the level of firm has been too narrow, focusing only on the recommendation but not on proper implementation aiming environmental performance. The outcome of analysis, thus, calls attention for a critical revision and adjustments to the policy on environmental quality management at the National and Provincial level in order to promote voluntary action by firms.

\section{ACKNOWLEDGEMENT}

Authors wish to express their gratitude to the South Asian Network for Development \& Environmental Economics (SANDEE) for providing financial assistance for carrying out this research study.

\section{REFERENCES}

De Vellis., R. F., 1991. Scale Development: Theory and Applications, Sage Publications, Newbury Park.

Hair., J. F., Anderson, R. E., Tatham, R. L., and Black, W. C., 2006. Multivariate data Analysis with Readings. Prentice Hall, Englewood Cliffs, New Jersey.

Henson, S., Heasman, M., 1998. Food Safety Regulation and the Firm: Understanding the Process of Compliance. Food Policy 23(1): 9-23.

Marcus, A. E., 1984. The Adversary Economy. Quorum Books, London, England.

Nehrt, C., 1998. Maintainability of First Mover Advantages When Environmental Regulations Differ Between Countries. Academy of Management Review 23(1): 77-97.

Peltzman, S., 1976. Towards a More General Theory of Regulation. Journal of Law and Economics. 19: 211240 .

Porter, M. E., van der Linde, C., 1995. Towards a New Conception of the Environment-Competitiveness Relationship. Journal of Economic Perspectives 9(4): 97-118.

Powers, D. A., Xie, Y., 1999. Statistical Methods for Categorical Data Analysis, Academic Press Inc

Rugman, A. M.,Verbeke, A., 1998. Corporate Strategies Environmental Regulations. Strategic Management Journal 19(4): 363-375.

Stigler, G., 1971. The Theory of Economic Regulation. Bell Journal of Economics and Management Science. 2: 3-21. 